\title{
Intelectuales y política en Perú. Un esquema
}

Osmar Gonzáles*

CES-EL COLEGIO DE MEXICO

Se estudia la relación de los intelectuales con la política desde el siglo XIv, hasta el presente, según el autor la fractura cultural propia de Perú explica que los intelectuales busquen como interlocutor al poder y a la política, y no a la sociedad con la que no comparten, muchas veces, ni un mismo lenguaje.

Q uien haya seguido atentamente la evolución de los intelectuales en Perú habrá observado la extrema facilidad, constancia y perseverancia con la que ellos transitan al campo de la política. Los intelectuales-políticos, o los políticos-intelec-

* Debo agradecer los comentarios que a la primera versión de este artículo hicieron Mario Constantino, Rodolfo Macías, Velia Cecilia Bobes y Fanni Muñoz, enriqueciéndolo enormemente. También dejo constancia de mi gratitud a los dos lectores anónimos que me ayudaron a precisar puntos que había pasado por alto. Aunque me aburre citar un lugar común tengo que ha. cerlo: no obstante, los errores son todos míos, no de ellos. tuales, no son personajes extraños en el panorama peruano. Por el contrario, pertenecen a lo más representativo de la vida social. Pero más allá de esta constatación, debemos preguntarnos cuáles son las razones que explican esta tan rápida "ida" ('huída?) de los intelectuales, a un campo que no les pertenece, ya que ellos tienen como función principal la de forjar los valores centrales de la sociedad, mientras que la política se ha centrado en la lucha por el control del poder.

Cuando me refiero a que los intelectuales establecen relaciones con la política considero que son dos los me- 
dios básicos por los cuales ellos quieren influir en las decisiones políticas. Uno sería el de ideólogos -en tanto que pensadores sociales con ciertas pretensiones de totalidad, aun cuando su totalidad referencial no coincida con la totalidad del país por razones que veremos después-, asesores o consejeros morales de la sociedad, ${ }^{1}$ característica del proceso social europeo occidental. ${ }^{2}$ Otro medio sería el de políticos propiamente dicho, para

\footnotetext{
I Aunque es dificil clasificar a los intelectuales según su participación en la vida pública, puesto que sus trayectorias no son ni lineales ni homogéneas, es posible distinguir a algunos nombres tomando como referencia hechos cla. ves de sus vidas, aunque sea sólo a título indiciario. De este modo, cuando pensamos en los ideólogos se nos vienen a la mente intelectuales como Juan Pablo Viscardo y Guzmán, Manuel Lorenzo Vidaurre, Bartolomé Herrera, los civilistas de La Revista de Lima, los positivistas, José de la Riva Agüero, Víctor Andrés Belaunde, Fancisco Miro Quesada, los ligados a la Nueva Izquierda, entre otros más. Como asesores es posible mencionar a Hipólito Unanue, José Baquijano y Carrillo, José Faustino Sánchez Carrión, Luis A. Flores, los intelectuales ligados al velasquismo y agrupados en el Sistema Nacional de Movilización Social (SINAMOS), Hernando de Soto. Como consejeros morales se puede ubicar a Francisco de Paula González Vigil, Mariano Amézaga, Manuel González Prada, Jorge Basadre. Reitero que esta lista no es para nada exhaustiva, sólo indicativa, además de que un mismo intelectual puede haber cumplido diferentes papeles a lo largo de toda su trayectoria.

${ }^{2}$ Respecto a los usos correctos de la literatura política, dice Carlos Fuentes: "Calvino escribe que la literatura es necesaria a la política cuando da voz a lo que carece de ella, o da nombre a lo que aún es anónimo." Fuentes, Valiente, 1994, p. 28. En los países latinoamericanos éste ha sido el principal papel que ha jugado la literatura, comprometiéndose siempre con alguna de las partes en conflicto y covirtiéndolo en una característica central de la naturaleza de su función.
}

lo que muestran gran vocación fundando partidos, organizando frentes, proponiéndose como candidatos presidenciales o parlamentarios, etc. ${ }^{3}$ En suma, los intelectuales en Perú (y creo que en todos los países de gran heterogeneidad cultural y precaria institucionalización) no sólo quieren influir en la política sino, más aún, desean ser parte de ella, aunque esto implique el abandono de su principal tarea como intelectuales, que es la de generar ideas, agitar el debate, someter a cuestionamiento constante el conocimiento legitimado.

Sobre estos argumentos deseo ofrecer un conjunto de proposiciones, ideas e hipótesis que permitan, si no responder, al menos acercarnos con nuevos elementos al problema señalado. Previamente deseo hacer una aclaración: cuando me refiero a los intelectuales peruanos aludo sólo a dos tipos de ellos: los pensadores sociales y los escritores, es decir, a quienes utilizan la palabra escrita como medio principal de comunicación y expresión, ${ }^{4}$ y excluyo de mi campo de

${ }^{3} \mathrm{Si}$ bien esto ha sido una constante en la vida republicana de Perú (sólo habría que revisar la lista de nombres de la primera Asamblea Constituyente de 1823), la participación de los intelectuales en las ofertas electorales cobra mayor relevancia en la década de los ochenta, esto es, cuando se retorna a la constitucionalidad luego de doce años de gobiernos militares. Y en este contexto el caso más destacado, sin duda alguna, es el del escritor Mario Vargas Llosa, quien fue candidato presidencial del frente liberal FREDEMO.

${ }^{4}$ Como se verá a lo largo del texto, me inspiro en la obra capital, aunque tomándola libremente en mi provecho, del libro de Coser, $\mathrm{Hom}$. bres, 1966. 


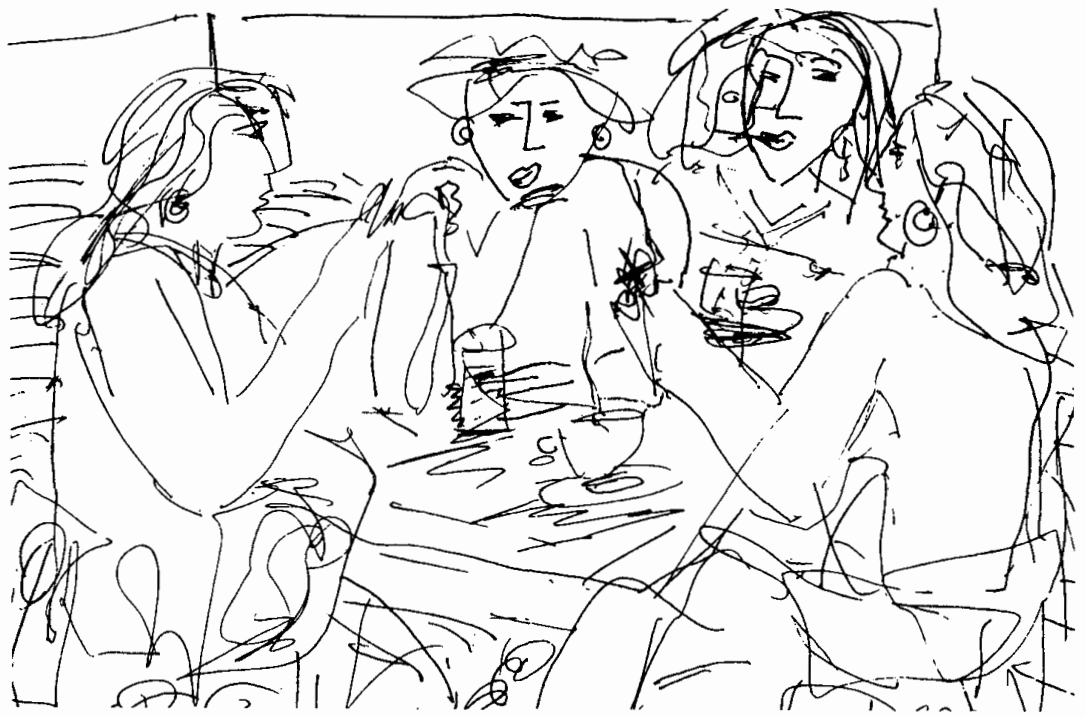

reflexión a otro tipo de intelectuales y artistas (los plásticos, los cineastas, los maestros, por ejemplo). Esto hace más limitado mi universo de analísis pero al mismo tiempo lo vuelve más preciso.

Para entender la manera específica en que los intelectuales se relacionan con la política en Perú, abordaré el tema desde los siguientes ejes: su vinculación con la sociedad y, en ésta, el papel del lenguaje; la existencia o no de valores aceptados universalmente, y la conformación de un mercado libre y anónimo para la producción in. telectual. ${ }^{5}$ Este puñado de reflexiones

\footnotetext{
5 Este esquema lo presenté de una manera más general y teórica en el artículo "Academia", 1995.
}

desean convertirse en proyecto de investigación sobre el papel de los intelectuales en Perú, por ello nada de lo que sigue tiene un carácter definitivo, ya que simplemente son propuestas de comprensión sobre las que hay que transitar con cuidado para no precipitarse a conclusiones apresuradas.

\section{EL INTELECTUAL EN LA SOCIEDAD COLONIAL}

Como ya señalé, cuando acudo al término "intelectual" (moderno) tengo como referencia al producto histórico de Occidente, a aquellos que utilizaron la palabra escrita como medio privilegiado de expresión y llegaron a nuestras tierras con la propia invasión 
española en el siglo xvI. ${ }^{6}$ Como es evidente, este sector constituyó sólo una pequeña porción de la población total en la organización colonial. No obstante, pudo convivir con aquellos otros que fungieron como intelectuales en la sociedad prehispánica, es decir, los que basaron en la oralidad la comunicación y la transmisión de conocimientos.

Pero, aunque se trataba de dos códigos distintos de expresión, no existió suplantación de uno por el otro. Al contrario, hubo traslapes, superposiciones, convivencias de tiempos históricos, continuidad, puesto que los cronistas españoles recogieron toda su información gracias a los relatos orales de quienes eran los depositarios del saber, de la historia y de las tradiciones de los pueblos indígenas.?

En una sociedad como la producida por la conquista, en la cual el pacto colonial sólo llegaba a algunas zonas donde se negociaba un acuerdo entre corona y sectores indígenas, o en las que predominaba la coacción y la represión; así como en otras donde el Estado colonial no tenía interés en llegar y, finalmente, aquellas a las que no alcanzaba el dominio colonial, ya fuera por desinterés o ineficacia, el resultado era una organización social jerárquica y fragmentada. En ese tipo

\footnotetext{
${ }^{6}$ En este sentido, y bajo dichos criterios, los primeros intelectuales en América fueron los cronistas que llegaron en las expediciones conquistadoras. Ellos tuvieron como misión, primero, relatar la historia de la conquista y las formas de vida de los pueblos que encontraron en tierras americanas. Al respecto ver el libro de Brading, Orbe, 1991.

${ }^{7}$ Sobre la relación entre expresión escrita y oral ver Ong, Oralidad, 1987.
}

de orden era fácil que la palabra escrita se considerara como un recurso que podía ser manipulado por sus poseedores para adquirir o ampliar su prestigio y estatus.

Desde la evidencia de esta ruptura debemos tratar de comprender la realidad en la que surgen los intelectuales en Perú. Así como tener presente esa escisión para analizar la relación que los intelectuales han establecido siem. pre con la política en nuestro país. La política puede ser considerada como medio o como fin, pero siempre será un referente ineludible. Será un medio, en tanto proporciona al intelectual prestigio ante los sectores sociales con los que busca establecer relación, y será un fin en tanto la política es buscada como interlocutora. En algunas circunstancias el medio termina siendo un fin en sí mismo.

Los casos más representativos pueden ser las obras del Inca Garcilaso de La Vega y de Guamán Poma de Ayala, básicamente Los comentarios reales y Nueva crónica y buen gobierno.

\section{ESE OTRO, EL PODER}

Ambos autores proyectaron sus reflexiones no hacia la sociedad sino hacia los terrenos del poder, en su caso, la corona española, más específicamente, el rey. El primero, ofrece una visión de la historia distinta a la relatada por los cronistas toledanos en la que aboga por otro trato para los indígenas. ${ }^{8}$ El segundo presenta reclamos

8 Al respecto ver Hernández, Memoria, 1993. Especialmente los capítulos referidos a la traduc. 
y remite a consejos para un mejor y más justo gobierno. ${ }^{9}$ Creo que ambos casos nos ayudan a ilustrar la relación establecida por los intelectuales con la política en Perú y nos pueden orientar en el necesario recorrido histórico por hacer.

Por todo ello resulta central preguntarse por qué esa rápida vinculación de los intelectuales con la política. Más aún si se trata, como es el caso, de un esquema que se repite a lo largo del tiempo. ¿Por qué la prioridad de los intelectuales de buscar como interlocutor al poder y no a la sociedad (para hablar en términos muy gruesos que obviamente necesitan ser refinados)? Es bueno señalar el hecho de que, desde la invasión española, se produjo el choque de, por lo menos, dos cosmovisiones, de dos procesos culturales. Digo por lo menos porque, como se sabe, se trató de dos realidades múltiples que se tocaron en el

ción que Garcilaso hizo de Diálogos de amor de León Hebreo, por medio de la cual el cronista trata de asumir su complicado origen; a la utilización de la escritura como vía de unión-de sus vertientes culturales, la oral prehispánica y la escrita occidental, a la vez de afirmación personal y de relación entre escritura y poder.

9 "No deja de llamar la atención -y sin embargo, era tan de esperarse- que en ese espacio singular [el mundo incaico], sacudido por transformaciones sísmicas, muy poco tiempo después aparecieran dos peruanos, cronistas mayores: Garcilaso el mestizo y el indígena Guamán Poma de Ayala. Desde el sosiego distante el uno y desde la zozobra andariega el otro, vertieron en palabras su experiencia. Ambos escritores, recogiendo sus más personales angustias, asían en importante medida la experiencia peruana de momentos fundantes, iniciaban la produc. ción de nuestro discurso cultural e inauguraban la reflexión americana." Hernández, Memoria, 1993 , p. 138. momento de la invasión española. Las contradicciones que este suceso implicó no se resolvieron ni por la vía de un mestizaje más o menos integrador, ni por la vía del exterminio. Por el contrario, se estableció la convivencia de dos formas de organización sociocultural, lo que trajo como consecuencia la fragmentación, simbolizada en la división administrativa como "república de indios" y "república de españoles".

Esta fragmentación no sólo se presentó en el terreno económico o social, sino, y quizás sobre todo, adquirió sus consecuencias más profundas y durables en el terreno cultural. En otras palabras, se trató de mantener a la población indígena al margen de la conformación de una sociedad nacional. En esto cumplió un papel importante la división estamental colonial. No obstante, eso no significó que no existieran filtros, vías de comunicación subterránea entre ambas cosmovisiones. La misma cantidad de bastardos nos habla de que, a pesar de la pretendida separación resguardada por la ley colonial, su poder restrictivo casi no existió en la vida real. ${ }^{10}$

\section{SÍMBOLOS Y LENGUAJE}

La consecuencia de este tipo de ordenamiento social fue la incapacidad de crear un conjunto de "símbolos emblemáticos"11 que hicieran comprensibles a los integrantes de la sociedad colonial, los mensajes emitidos

\footnotetext{
10 Véase Flores, Buscando, 1987.

11 Durkheim, Formas, 1993.
} 
por la realidad. Y es en esa creación simbólica donde el lenguaje hubiera debido cumplir un papel primordial. ${ }^{12}$ Pero lo que sucedió fue lo contrario, pues por ser el español el idioma hegemónico (medio de comunicación de quienes controlaban el poder), y la población hispanohablante numéricamente reducida (y mucho más reducida aún la población hispanoescribiente), era prácticamente inexistente la posibilidad de constituir un conjunto de códigos y símbolos compartidos.

En este contexto, surgen como problemas la manera y la vía en que aquellos mestizos educados podían comunicar sus vivencias y relacionarse con la sociedad de su época. En verdad, sólo tenían una opción por delante: apropiarse del lenguaje hegemónico para adquirir notoriedad social, aunque ello significara desvincularse de la población mayoritaria, la indígena. Es por ello que el uso del lenguaje no fue un elemento vinculador de la sociedad, y menos uno que contribuyera a la formación de valores y a modelos humanos aceptados por todos.

Quizás esta imposibilidad universalista explique por qué algunos intelectuales no optaron por la asunción crí-

12 "Examinada generosamente en cuanto a cadencia y timbre, léxico y sintaxis, modismos e imágenes, la lengua brinda al historiador algunas de las claves más valiosas de la experiencia social. La lengua registra toda la gama de actividades o perspectivas de un pueblo; conserva las tradiciones y da cabida a los temas del momento; todos la usan y moldean, el plebeyo y el patricio, el iletrado y el erudito; pinta el extenso panorama de la sociedad así como sus pormenores. La lengua es heteroglosa de pies a cabeza." Morse, Resonancias, 1995, pp. 29-30. tica de los problemas sociales vigentes, dado que ello suponía cuestionar desde la raiz el orden colonial al que no podían reemplazar, sino que priorizaran el uso de la ironía, de la disolución de las jerarquías establecidas por medio de la burla. El mejor ejemplo quizás lo constituya Caviedes y su crítica mordaz de los médicos. En él no hay programa, sólo sublimación de un estado de ánimo. ${ }^{13}$

Para resumir, las divisiones étnicas, culturales y estamentales actuaron como bloqueadores para la integración no sólo económica y social, sino también simbólica.

\section{EL MANTENIMIENTO DE LA ESCISIÓN CULTURAL}

De este modo, el poder terminó siendo identificado con una minoría perteneciente a un específico componente étnico, que controlaba los recursos económicos y poseía los valores cultu. rales necesarios para mantenerse en esa posición de dominio. Los espacios de decisión e influencia eran restringidos y la pretensión de modificar la situación dada sólo podía intentarse por la vía de la insurrección o por medio de la apropiación de esos bienes

\footnotetext{
13 En la línea criollista de Caviedes se en cuentra una rica tradición de la literatura peruana, en la cual se puede mencionar a Manuel Asencio Segura, Felipe Pardo y Aliaga, Manuel Atanasio Fuentes, Ricardo Palma, Leonidas Yerovi, José Gálvez. Posteriormente, sin dejar ese carácter risueño e irónico, pero agregándole dosis de cuestionamiento social, se encuentran escritores como José Diez Canseco y Alfredo Bryce Echenique.
} 
culturales para poder influir aunque sea dentro de una pequeña franja social. La posición privilegiada para aprovechar esos bienes por parte de los intelectuales hace que opten por el segundo camino.

La forma de organización propia de la colonia someramente descrita se mantuvo durante la república. Luego de la independencia siguió la fragmentación en todos los niveles de la vida social, las pugnas entre caudillos militares prácticamente hicieron desapareceral Estado y una nueva institucionalidad estaba muy lejos de concretarse. En esta situación, los intelectuales perdieron aún más un referente único o universal al cual dirigirse, por lo que su diálogo directo fue con algunas de las distintas fracciones en pugna. Las polémicas entre liberales y conservadores, encabezadas por los hermanos Gálvez y el cura Bartolomé Herrera, no se dieron sobre la base $-\mathrm{y}$ al frente-de un Estado constituido, sino que nos muestran un terreno en el que ninguna de las partes había conseguido la hegemonía. El Estado peruano era todavía un concepto por crear.

La relativa modernización y el in. greso de capitales producido por la riqueza natural guanera a mediados del siglo XIX, produjo un cierto ensanchamiento de la vida política, social y cultural. Al enriquecimiento de las elites acompañó una movilización por parte de algunos sectores de la sociedad, especialmente urbanos, que inician su camino organizativo bajo las ideas del mutualismo. En este momento se perfilan tres figuras de intelectuales más o menos clásicas. Por un lado, el intelectual que asume directamente un papel político, como fue el caso de Manuel Pardo, fundador del Partido Civil (1872) y primer presidente civil luego de fundada la república. Por otro, el intelectual que frente al poder trata de convertirse en un foco moral de la sociedad, más por sus actitudes que por su tesitura reflexiva (que también la tuvo, pero menos significativa), como Mariano Amézaga. Finalmente, surge el intelectual asesor de los grupos de artesanos y primeros obreros que buscaban asociarse, como fue Francisco González de Paula Vigil.

Después de la derrota en la guerra de 1879 con Chile, surgió la necesidad de centralizar mínimamente un Estado y cohesionar cierto tipo de sociedad. El fracaso militar y político de la guerra no sólo significó postergar la construcción de una nación, sino también hizo su aparición el "disidente", encarnado en el gran pensador anarquista Manuel González Prada, quien, con su verbo vibrante y sus acusaciones fulminantes contra la corrupción e ineptitud de las elites, representó un intento por cambiar (al menos en el discurso) un tipo de relación entre Estado y sociedad que se basaba en la discriminación de los mayoritarios contingentes indígenas.

No obstante, ya de concluida la guerra, se muestran los contornos de una época en que se revela un mayor interés de parte de las elites por construir un Estado estable y sujeto a ciertas reglas durante la época del domi. nio oligárquico (1895-1968). El fin del militarismo posguerra y un relativo auge económico por el incremento de la agroexportación no significó el in greso del país a una etapa de democra- 
tización social y política. A lo sumo se abrieron las puertas a una relativa modernización sin modernidad, al menos en gran parte de los sectores dominantes.

Por el contrario, las elites oligárquicas siguieron esforzándose por marcar sus diferencias con el resto de la sociedad, constituida por grupos provenientes de diferentes tradiciones culturales que se consideraban arcaicas, ubicados en los rangos más bajos de la república oligárquica, especialmente las razas "de color". Estableciendo un orden político y social exclusivo $y$ excluyente, las familias oligárquicas ${ }^{14}$ se esmeraron por mantener su vinculación con la cultura europea en vez de plantearse seriamente el objetivo de construir un Estado nacional integrador, inclusivo, representativo de la pluralidad peruana de ese entonces. A lo más se llegaba a incorporar a los sectores populares a la nacionalidad en tanto representaban la "sangre y el músculo" del país. El eje de este orden lo constituyeron las haciendas, en cuyo centro la población indígena, utilizada como fuerza de trabajo, se sometía al poder del hacendado, quien tenía la autonomía suficiente para ejercer la justicia y regular el proceso económico.

Por medio de mecanismos como el compadrazgo y ejerciendo alternativamente la represión y el paternalismo, et hacendado mantenía el orden social en el interior de sus propiedades. Los

${ }^{14}$ Las alianzas familiares, vía matrimonial, fueron frecuentes en la conformación de los Estados latinoamericanos. Al respecto ver Balmori, Alianzas, 1990. hacendados más prósperos tenían mejores condiciones para vincularse con el mercado exterior, como lo representan los "barones del azúcar" del norte, o los comerciantes laneros del sur. Esta vinculación les permitió el enriquecimiento, el mantenimiento del poder político pero con el déficit que significaba terminar siendo culturalmente "forasteros". Un ejemplo claro de esto último es que las elites que controlaban el poder se educaban especialmente en Europa primero, o en Estados Unidos después, tratando de imitar patrones de vida foráneos y buscando incorporarse a su cultura. Es por ello que los integrantes de las familias oligárquicas podían conocer idiomas como el francés, el alemán, el inglés, y se distanciaban más aún del grueso de la sociedad peruana. ${ }^{15}$

\section{LA OPCIÓN DEL INTELECTUAL}

Más allá de la imagen estática que nos ha quedado de la sociedad oligárquica, hay que decir que, por el contrario, se trató de una sociedad profundamente movilizada, producto justamente de las contradicciones que generaba el sistema de dominio sociocultural descrito. Los amplios sectores de campesinos que se rebelaban contra la apropiación feudal, los emergentes sectores urbanos, es decir, obreros, artesanos y clases medias, la ampliación de los círculos intelectuales, entre otros procesos, nos hablan de una sociedad sumamente activa.

15 Un libro importante al respecto es el de Burga y Flores, Apogeo, 1980. 
Los procesos de modernización y urbanización, si bien no pudieron romper el espinazo del orden oligárquico, prepararon su funeral. Esto es válido tanto por los procesos como por los actores que ayudaron al surgimiento y consolidación. El protopopulismo de Billinghurst, el gobierno modernizador de Leguía, las ideologías revolucionarias del aprismo y del socialismo, las confrontaciones civiles de los treinta, la aparición de incipientes sectores de burguesía nacional después, expresan que el dominio oligárquico no fue tan terso y sin sobresaltos como a menudo se cree. Por lo cual no se explicaría la apelación al ejército, que dio origen a la alianza civil-militarista.

De manera subterránea al endurecimiento del Estado se desenvuelve un proceso incesante por parte de aquellos sectores sociales excluidos que buscan ser incorporados a la vida nacional, tanto a nivel productivo como político y social. El resultado es, aun cuando no siempre de manera consciente, una exigencia por la ampliación de la ciudadanía.

Evidentemente se trata de una sociedad no sólo movilizada sino también polarizada. Dentro de su propia vivencia, los intelectuales reproducen la tragedia que, en otro plano, experimenta el mestizo: no pertenecen a ninguno de los dos mundos en conflicto de manera absoluta. Por lo tanto, pueden optar por dos salidas. O por la incorporación al mundo criollo blanco occidental, o por su oposición a él. En otras palabras, el intelectual en Perú no sólo está en medio de los conflictos sino que es parte de ellos. No puede colocarse al margen.
LA PARADOJa DEL INTELECTUAL PERUANO

La paradoja es que éste se beneficia de la sociedad criolla por el lenguaje y por ciertos valores culturales. Pero esto lo coloca en una pequeña franja de la nacionalidad. No lo ubica en el centro del terreno fecundo de la sociedad amplia, que es en donde justamente debe recabar su legitimidad. Esta ubicación no deseada le impide cumplir con la tarea del intelectual moderno, que es la de generar y expandir los valores centrales de la sociedad. ${ }^{16}$

En otras palabras, en donde adquiere el lenguaje no encuentra la posibilidad de comunicarse con los diferentes sectores constituyentes de la nacionalidad. Y en donde sí debe recabar su legitimidad, fomentando los valores centrales o comunes, no halla el lenguaje que le permita transmitir las experiencias y modelar prototipos de seres humanos ideales y aceptados. ${ }^{17}$ Se trata de dos mundos incompletos en que el intelectual debe optar para sobrevivir. Pero la tensión puede ser mortal, colocándolo en una esquizo-

16 Por ello, la otra salida para el intelectual puede ser el deleite en la creación pura, como José María Eguren, Martín Adán, Javier Sologuren, Germán Belli.

${ }^{17}$ Aunque ello no niegue la existencia de intentos. Quizás los casos más representativos sean los textos de Mario Vargas Llosa y Julio Ramón Ribeyro, aunque sus personajes sean urbanos, cuando no urbano-marginales. Desde el mundo andino se pueden mencionar los cuentos y novelas de José María Arguedas. Abraham Valdelomar esboza tipos humanos pero referidos especialmente al mundo criollo-provincia. no-pobre. Pero quien en definitiva trató de ser el más universal ha sido sobre todo el poeta César Vallejo. 
frenia que no siempre es capaz de resistir. Quizás esta pista pueda ayudar a entender el suicidio del novelista mestizo e indigenista José María Arguedas.

Lo peculiar de Arguedas es que, en primer lugar, su mismo lenguaje trató de ser una simbiosis que expresara los valores culturales tanto del mundo andino como del occidental. Además, el uso que le dio al lenguaje fue con la intención de apropiarse de él para tratar de expresar experiencias, sentimientos y situaciones que provenían de la otra cultura de la que lo había tomado. Su novela póstuma, El zorro de arriba y el zorro de abajo, es la mejor expresión de este intento de fusionar apropiación de lenguaje con búsqueda de legitimación en una sociedad "hirviente", como él la definió. ${ }^{18}$ Es decir, caracterizada por procesos de relaciones y vinculaciones inéditas entre las diversas culturas y grupos étnicos conformantes de la sociedad peruana.

Arguedas, al menos el Arguedas final, no utilizó el lenguaje para oponer-

18 "A falta de una perspectiva histórica, Arguedas en 1939 sentía 'la agonía del español como clima espiritual y lengua pura e intacta'. No perseguía el triunfo guerrero y político de una lengua ni su absorción evolutiva [...]Aun cuando pudiera demostrarse que el español de las tierras altas ha tomado el sello del sustrato quechua, esto no significa necesariamente que haya habido transferencia de la comprensión conceptual o del punto de vista espiritual [...] Lo que buscaba entre las lenguas del Perú era una 'pluralidad discursiva' o la 'identidad combinatoria' que fuera translingüistica y transcultural. Dentro de este universo plural, veía al quechua y al español como 'copresentes' [...] Tanto Dante como Arguedas se enfrentaron a la transición de un mundo agónico a los primeros vagidos del otro." Morse, Resonancias, 1995, pp. 93-94. se sin concesiones a lo occidental sino para, en su apropiación, hacerle hablar de las experiencias de los que habían quedado sin posibilidad de expresarse. Su propósito fue distinto, por ejemplo, al del joven Luis E. Valcárcel, que utilizaba el lenguaje del "otro" para anunciar la destrucción de su cultura, por medio de la tempestad que, anunciaba, iba a bajar desde los Andes. 19

Los casos ejemplificadores pueden ser numerosos. Sin embargo, no me interesa ser exhaustivo. Simplemente deseo dejar más o menos clara la idea sobre la posición del intelectual en una sociedad escindida como la peruana. La "insularidad" del intelectual actúa como un factor contextual que lo empuja a tomar decisiones, a elegir una opción. Generalmente, las ambigüedades salen sobrando, aunque no se puede decir que se trate de una ley intransgredible.

\section{LOS CONFLICTOS SOCIALES Y LA POSICIÓN DEL INTELECTUAL}

Esto último me lleva al otro tema, consustancial al anterior (el de la ausencia

19 "Por eso mismo, [porque Valcárcel no es indio] se yergue furioso contra la fénula de la Academia y propone una ortografia original, que ya usan muchos. Me limito a objetar pancescamente. Nada ganamos reemplazando el 'gua' español con la 'w', que no es peruana, sino sajona. Tampoco ganamos mucho con sustituir la 'c' fuerte por una ' $k$ ', que tampoco es peruana, sino germana. Pasar de Madrid a Berlín y Londres, no nos da el derrotero del autoctonismo [...] El quechua lo que requiere es uniformar la grafia y la prosodia". Sánchez, "Colofón", 1972, p. 182. 
e imposibilidad de constituir los llamados valores centrales de la sociedad). Me refiero al de la práctica del intelectual.

Había comenzado recordando los casos de dos cronistas mestizo-indígenas de inicios de la dominación colonial y su necesidad de comunicarse con lo que constituía el poder. Esta necesidad se explica, continuaba, tanto por la ausencia de un lenguaje común como por la inexistencia de valores compartidos. Por lo tanto, frente a esta situación el intelectual está obligado a tomar decisiones.

Lo que quiero destacar es que, en una sociedad escindida culturalmente, el intelectual no puede desarrollarse como lo hicieron los escritores de la Europa del siglo XVII-XVIII, quienes de alguna manera se convirtieron en los dioses terrenales de sus respectivos países, en santos laicos que ocuparon el lugar dejado por los dioses celestiales durante el proceso de secularización. ${ }^{20}$

Es decir, los intelectuales en Perú no pueden convertirse en los grandes referentes de una "comunidad imaginada" más allá de las disputas de las fracciones. ${ }^{21}$ Por el contrario, como

20 Benichou, Coronación, 1990.

${ }^{21}$ Una nación es una comunidad en tanto implica un compañerismo profundo y horizontal entre sus integrantes, aun cuando es imposible que todos se conozcan. Es imaginada porque esa imagen de comunión está presente en la mente de cada uno. Al mismo tiempo, la nación es limitada porque tiene fronteras finitas aunque elásticas, y es soberana por sus sueños de libertad, y porque está representada en el Estado soberano. Anderson, Comunidades, 1993. En el Perú diferentes autores reclamaron esta comunidad, aunque llamándola de distintas ma- señalé, son parte de esas fracciones. El concepto de encarnación de la totalidad está ausente en ellos. Quizás esto explique por qué, al menos en el presente siglo, los personajes más representativos sean Mariátegui y Haya de la Torre, quienes trataron de dar forma a una sociedad nacional desde la experiencia del conflicto, ${ }^{22}$ lo cual querría decir que, estructuralmente, hay un campo intelectual sin instituciones que le den sustancia. ${ }^{23} \mathrm{Y}$ ello lleva al intelectual a buscar su legitimidad en otros ámbitos, especialmente en el de la política. Para decirlo de una manera más sociológica, el terreno de la politica le ofrece al intelectual lo que en su propio campo no encuentra, es decir, comunicarse con la sociedad total; pero, siempre encerrado en su paradoja, cuando lo consigue lo hace al costo de renunciar a su ser como intelectual. Resulta terminando otro en otra parte.

neras. Belaunde reclamaba que no hayamos sabido forjar un ideal; Riva Agüero decía que había que recuperar el alma nacional; Basadre afirmaba que aún era posible cumplir con la promesa de la vida peruana, entre otros ejemplos.

22 Por otro lado, la imposibilidad de construir un discurso hegemónico y totalizador lleva a los intelectuales al enfrentamiento contra el sistema establecido de valores e ideas. Casos representativos en el Perú son los colónidas, los indigenistas, los comunistas.

${ }^{23}$ Bourdieu señala que si bien el campo intelectual y el del poder tienen gran autonomía, el primero está determinado "por el lugar que ocupa en el interior del campo de poder". Además, el campo intelectual se debe constituir como "un sistema de posiciones que exige clases de agentes provistos de cualidades determinadas (socialmente constituidas) [esto es, intelectuales, artistas, escritores], tal como un mercado de trabajo exige puestos". Bourdieu, Campo, 1983, p. 21. 


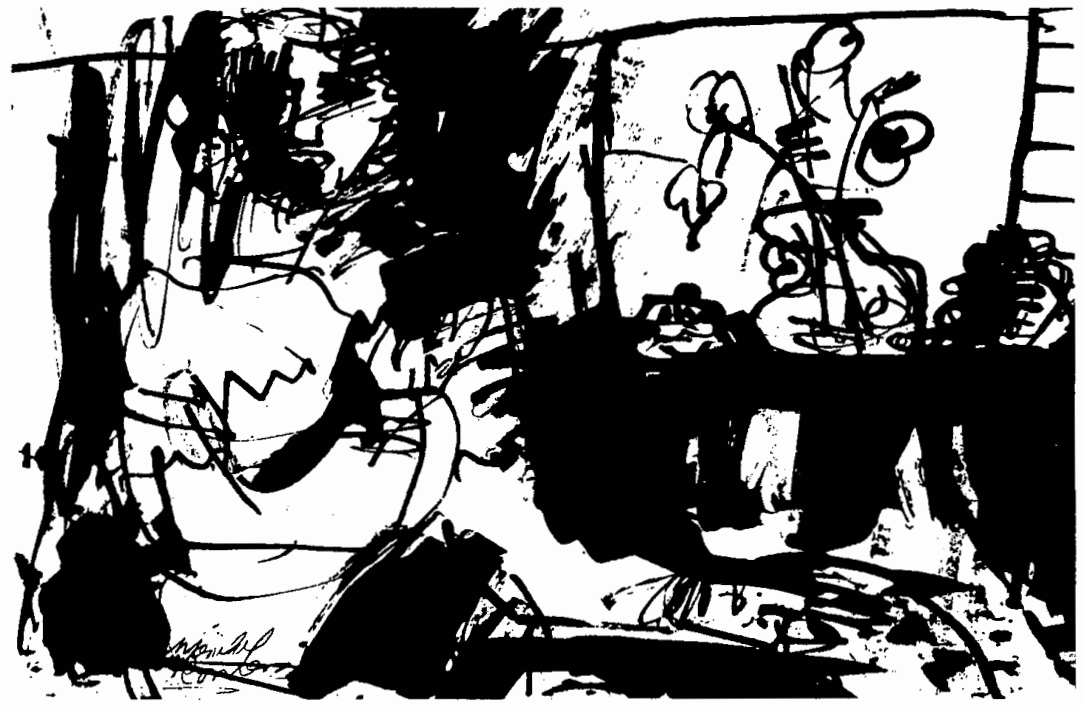

La ausencia de un campo intelectual vuelve difícil que los intelectuales se reproduzcan como tales y obtengan legitimidad social. Esta manera de ver el problema los ubica en su entorno, y permite ver, además, no sólo a los intelectuales sino también a lo intelectual. ${ }^{24}$

La posición escindida y confronta. da posiblemente nos ayude a explicar

24 Creo que las dificultades que se derivan de privilegiar a los intelectuales dejando de lado a lo intelectual, están bien ejemplificadas en el artículo de Sinesio López "Intelectuales y políticos en el Perú del siglo $\mathrm{xx}^{n}$, en donde propone un esquema de análisis sobre la manera en que los intelectuales se relacionan con la política pero dejando de lado casi completamente los factores contextuales. En Adrianzén, Pensamiento, 1990. por qué en Perú, como en el resto de los países latinoamericanos, salvo algunas raras excepciones, no han florecido los filósofos, es decir, aquellos pensadores que, elevándose sobre su sociedad, sean capaces de dar un sentido a lo que se presenta incoherente, de dar unidad a lo que aparece disperso. ${ }^{25}$ Las condiciones son otras, y distintas, según lo que hemos visto. Por el contrario, los filósofos han sido, en muchos casos, dirigentes políticos,

25 Es por esta característica que Alberto Adrianzén señala con razón que no era casual que en el Perú no se escribiera un drama universal como Romeo y Julieta, sino otros en que las diversas escisiones del país aparecían en toda su dramática dimensión, como en la novela de Enrique López Albújar, Matalaché. Véase Adrianzén, "Pacto", 1990. 
miembros de agrupaciones cuya meta era llegar al poder, al control del Estado, a ser parte de los gobiernos. Las figuras del consenso han sido prácticamente escasas.

Podemos recordar los casos de Francisco Miró Quesada (de Acción Popular), de Alfonso Cobián (de la Democracia Cristiana), de Augusto Salazar Bondy (del Movimiento Social Progresista). Todos estos partidos fueron formados en la mitad del presente siglo, es decir, bajo un proceso más o menos sostenido de urbanización, de desarrollo y de modernización capitalista. $^{26}$

EL INTELECTUAL, EL MERCADO Y EL PÚBLICO

Recordar la presencia de estos procesos es importante, puesto que permite plantearnos el tema de si es posible o no la constitución de un mercado en el cual los intelectuales puedan reproducirse como tales.

Las migraciones producidas desde los años cuarenta y cincuenta, la corrosión del orden oligárquico, la presión por la ampliación de la ciudadanía, la lucha por mayores derechos reconocidos en el Estado, la expan-

26 La mención de estos casos no significa que no existieran otros. Podemos citar al Partido Nacional Democrático de José de la Riva Agüero, al Partido Liberal de Francisco Mostajo, o al Social Republicano de Jorge Basadre y Antonio Encinas. Pero podemos retroceder aún más en el tiempo, a los propios inicios de los partidos politicos en el Perú, y preguntarnos eel Partido Civil fundado por Manuel Pardo en el siglo XIX no concuerda, acaso, con las características de los señalados? sión de la educación y la mayor democratización de la universidad, son procesos de indudable trascendencia en la historia reciente del Perú. A pesar de ello, las divisiones estamentales de la sociedad y la persistencia de la mentalidad oligárquica fueron hechos demasiado persistentes, aun en la nueva realidad que se iba moldeando al amparo de procesos de modernización capitalista, por la vía del desarrollo por sustitución de importaciones.

Es cierto que los nuevos contingentes provincianos que se asentaban en las principales ciudades del país constituyeron fuerzas democratizadoras frente al orden oligárquico. Especialmente porque permitieron e impulsaron procesos de reconocimiento de múltiples sujetos como peruanos. Lo lejano, es decir, lo andino, aquellos personajes de piel cobriza y ropa tradicional, se instalaba en los centros de la modernidad nacional, especialmente en Lima. Los estereotipos formados desde la enseñanza escolar dejaban de ser meras alusiones a un mundo remoto. Ahora aquellos sujetos adquirían vida y corporeidad. Ya no se podía negar su existencia.

Muchos analistas han visto estos procesos como representativos de los periodos formativos de la nacionalidad. ${ }^{27}$ Pero hay que poner nuestra atención en que, a pesar de que esto sea cierto, la formación de un mercado para los intelectuales estaba lejos de concretarse. Es decir, aún no se

${ }^{27}$ Se pueden mencionar los trabajos de Franco, "Nación”, 1985; López, "Movilización", 1989; Matos, Desborde, 1985; Degregori, Blondet y Lynch, Conquistadores, 1986, entre otros textos en que se podría incluir De Soto, Otro, 1986. 
constituía un público que consumiera de manera masiva aquellos productos culturales que los intelectuales podrían ofrecer. Es bueno mencionar un intento como caso ilustrativo: el escritor Manuel Scorza fue el impulsor de una edición a bajo costo de una colección de obras consideradas clásicas. Las denominó Populibros. Era un esfuerzo por llevar la cultura al pueblo. Sin embargo, a pesar de la inversión editorial que significó, no constituyó el éxito comercial que se esperaba. Paralelamente, llegó al Perú el boom de la novela latinoamericana, que tenía a Mario Vargas Llosa como el máximo representante nacional. Su éxito es indudable, no sólo literario sino también comercial. Es decir, el mercado reveló que se encontraba en el extranjero, especialmente en Europa, no en Perú. Por ello, Scorza se instaló en el viejo continente y desde alli proyectó su obra literaria. ${ }^{28}$

El problema del mercado literario es algo más profundo que el simple movimiento de compraventa de libros. Requiere de una condición previa: que haya una comunicación mínima entre productor y receptor, entre escritor y lector. Y para esto es necesario compartir ciertos valores, gustos, sentimientos, una cierta visión del mundo en suma. Los procesos y sujetos aparecidos en la mitad de siglo, propiciaron la perspectiva de un campo más nacional de comunicación. Los contingentes étnicos (criollos, indios, negros y mestizos) confluyen, aunque no sin contradicciones y recelos. ${ }^{29}$

\footnotetext{
28 Agradezco esta información a Jorge Nieto.
}

29 Franco, "Sentido", 1993.
Las clases sociales aparecen tam. bién compartiendo espacios que antes eran parte de los cotos cerrados de algunas elites. La ciudad se democratiza. Lima, especialmente, se comienza a andinizar. Las calles son tomadas por los contingentes antes postergados. Todo lo mencionado es inusitadamente rematado e impulsado por el reformismo velasquista. El velasquismo puede ser interpretado como consecuencia de los procesos sociales descritos. Las migraciones, de manera fundamental, coadyuvaron a la emergencia de nuevos sujetos. Se constituye la nueva plebe urbana ${ }^{30}$ y se produce un desborde popular, ${ }^{31}$ para utilizar dos términos exitosos de la literatura sociológica reciente.

\section{LA AMBIGÜEDAD DE LOS INTELECTUALES DE IZQUIERDA}

No es mi propósito entrar en el análisis del velasquismo en tanto régimen político. Lo que sí quiero es mostrar las claves sociales nuevas que se manifiestan y sobre las cuales los intelectuales tendrán que actuar y, claro, pensar. En este sentido, lo que es necesario poner de relieve es que dichos "nuevos sujetos" (nueva clase obrera, producto de la industrialización por sustitución de importaciones, pobladores de los llamados pueblos jóvenes o barriadas, nuevas generaciones de migrantes, sectores intelectuales en una universidad democratizada o aplebeyada) fueron parte de una sociedad

$30 \mathrm{Ibid}$, Otra, 1991.

31 Matos, Desborde, 1980. 
que se conformaba de manera mole. cular, constante e incesantemente.

La necesidad que surgió y que se hará cada vez más evidente, aun en la actualidad, es que era preciso que esta conformación social inédita produjera sus propios representantes. Esto es válido tanto para lo intelectual como para lo político. En lo político, la crisis actual de los partidos se puede explicar por este desfase entre sujetos sociales nuevos y emergentes y representaciones políticas (incluido el Estado) "viejas". Es decir, éstas continuaron como parte de una mentalidad anterior, profundamente permeada por la educación y socialización en tiempos de la oligarquía.

Pero además, los propios dirigentes pertenecían a las franjas sociales que justamente estaban en retroceso ante el avance de la cholificación del Perú (término propagandizado por Aníbal Quijano). Este desfase ya hizo eclosión. El sistema político levantado sobre este espejismo acaba de colapsar. $\mathrm{Y}$ de ello no escapa la izquierda, vista en alguna oportunidad como una alternativa distinta de construcción de sociedad. Los principales dirigentes de la nueva izquierda, surgida especialmente de los claustros universitarios modificados, seguían perteneciendo a los sectores criollos de clase media. Los cholos aún no podían segregar sus propios representantes, como están ahora en condiciones de hacerlo, según muchos observadores.

Lo mismo ocurrió en el plano intelectual. La pugna en las universidades fue dura para los sectores emergentes que debían imponer a sus propios intelectuales. Por el contrario, éstos se- guían perteneciendo, al menos en sus representantes más importantes y visibles, al igual que los líderes políticos, a los sectores criollos. Es decir, al componente minoritario de la sociedad peruana.

La ambigüedad de la izquierda es la siguiente: su discurso defendía la justicia de los desheredados y su control directo del poder, pero quienes tenían el privilegio de la palabra eran justamente quienes no pertenecían a esos contingentes mayoritarios a los cuales se apelaba. Esto produjo un gran sentimiento de culpa a sus miembros. Los intelectuales y políticos de la izquierda actuaban como "intérpretes" del pueblo (por lo demás, coherentes con la ideología leninista de llevarle conciencia de sus intereses y derechos) lo que resultó como la reproducción de una forma de relación jerárquica entre dirigentes y dirigidos, donde mucho tenían que ver las diferencias culturales. ${ }^{32}$

Producto de esta ambigüedad y sentimiento de culpa, la ideología socialista se encargó de edificar una imagen benigna y dulzona del pueblo. En esta producción ideológica hay que subrayar el papel de la educación católica y en especial de la teología de la liberación, en la visión que la izquierda tuvo del pueblo y del cambio social. ${ }^{33}$

Es evidente que los intelectuales de izquierda coadyuvaron a una recupe-

${ }^{32}$ Sobre una discusión acerca de la mentalidad de la izquierda surgida desde los años sesenta, véase Gonzáles, "Seducción", 1994. También el conversatorio Generación, 1994.

${ }^{33}$ Este tema lo desarrollo con mayor extensión en mi tesis "Señales", 1994. 
ración del papel de las multitudes en la conformación histórica peruana. Tam. bién es cierto que sus reflexiones abrieron nuevas temáticas e hipótesis, ${ }^{34}$ en la comprensión del proceso peruano, distintas a las que habían hegemonizado la enseñanza nacional, heredera principalmente de los intelectuales de inicios del siglo Xx. Pero más allá de esta influencia importante, en lo que hay que incidir es en que la intelectualidad seguía reproduciéndose por afuera de los sectores sociales significativos. Nuevamente, regresamos a lo mencionado líneas arriba: que el intelectual, para subsistir, debe ubicarse en uno de los polos del conflicto. Y el intelectual socialista es un caso ejemplificador. 35

${ }^{34}$ Por ejemplo, una revisión de los procesos de la independencia nacional y de la guerra con Chile, el problema de la identidad nacional, la participación popular en la construcción de la nacionalidad, el tema de la utopía andina, entre otros.

35 Este desacomodo o desencuentro entre un bien cultural (el lenguaje) y la inexistencia de un campo legitimante de él, es campo propicio para que emerjan posturas extremadamente radicales. Un ejemplo puede ser el mencionado de los indigenistas, pero otro, y más actual, el de los intelectuales senderistas, quienes suman además el marxismo-leninismo, y producen una de las propuestas marxistas más "frías" de las que surgen en el Perú durante los años sesenta y setenta, imperando, soberana, la Razón. "La de SL pretende ser [...] una epopeya cósmica. Para cuiminarla, cual intelectuales/guerreros al servicio de esa ciencia exactísima que regula el universo como un desmesurado ballet cósmico, tienen que ordenarlo y planificarlo todo de acuerdo al Libro, de acuerdo al marxismo-leninismo-maósmo, venciendo o destruyendo lo que se oponga a sus leyes ineluctables". Degregori, Difíctl, 1989, p. 24.

\section{LAS ONG Y LA INSTITUCIONALIZACIÓN DE LOS INTELECTUALES}

En la reproducción ideológica es claro que ejerció una influencia gravitante la enseñanza escolar, como lo han demostrado Gonzalo Portocarrero y Patricia Oliart. ${ }^{36}$ Pero no se puede soslayar el papel que cumplieron los Organismos No Gubernamentales (ONG). La importancia de las ONG tiene un doble sentido. Por un lado, el maceramiento y la difusión de un pensamiento que trataba de ser alternativo al predominante, la publicación de textos con lecturas renovadoras de la realidad nacional, la asesoría a las distintas organizaciones sociales, la reflexión sobre la política desde otras perspectivas, son sus principales aportes. Por el otro, la profesionalización e institucionalización de los intelectuales. Por medio de las ONG muchos intelectuales tienen la posibilidad de ser reconocidos como una voz importante dentro del debate nacional. Desde su labor pueden acceder a los medios de comunicación masiva como la televisión o la radio, por ejemplo. Con la plataforma de las ONG los intelectuales son capaces de incidir en la formación de una opinión pública y de participar en los acontecimientos políticos. ${ }^{37}$ Pero justamente esta institucionalización, que debe ser vista como un logro, oca-

36 Portocarrero y Oliart, Perú, 1989.

${ }^{37}$ Ahora, con el avance de las telecomunicaciones, el intelectual puede aprovechar los mass media pero sin poder solucionar el problema de fondo, esto es, el de lograr una comunicación esencial con el público, limitando así su impacto a lo inmediato, espectacular y efimero. Sobre estos temas ver el libro de Sarlo, Escenas, 1994. 
siona que el desfase entre intelectuales y sociedad se profundice. Nuevamente el diálogo de los intelectuales busca las esferas del poder, de la politica, del ámbito en donde se toman las decisiones. Podemos decirlo con una metáfora shakespereana: Calibán no puede apropiarse de la palabra, y Ariel sigue revoloteando por los alrededores del poder y la política, por los dominios de Próspero. ${ }^{38}$

\section{EL ARRIBO DE LOS EXPERTOS}

Los intelectuales, como decía en líneas anteriores, necesitan del terreno de lo político para ser partícipes importantes de la vida nacional. Y esto puede ser mucho más visible en los actuales momentos en que han caído las grandes utopías (especialmente el socialismo), donde han perdido legitimidad las macrointerpretaciones, donde las ideologías carecen de capacidad de seducción. En este momento, decía, es cuando aparecen copando el escenario los "expertos".

Los así llamados tienen una ventaja: aparecen ante la opinión pública como desprovistos de toda intencionalidad, de seres completamente racionales,

38 Muy vinculado a lo dicho está el reclamo que hace Guillermo Rochabrún cuando dice: "La ausencia de autonomía entre los espacios de la teoría, la política y la práctica profesional lleva a la constitución de una ciencia [la sociología] que se sitúa por debajo de las exigencias del presente. Si esto es así, al menos parte de la solución consiste en reconstruir la autonomía del mundo académico. La mejor colaboración que puede obtenerse es la que proviene de cam. pos tan bien decantados como sea posible". Rochabrún, "Política", 1993, p. 170. cuyas cualidades de tecnócratas los preservan de toda animosidad, de toda parcialidad, como si estuvieran por encima de los conflictos sociales porque son "los que saben", los pragmáticos. Supuestamente se caracterizan por buscar la mejor manera de hacer lo necesario dentro de un mundo ya esterilizado. Los ideólogos, que han fracasado, no tienen otra alternativa que cederles su lugar.

El problema que genera esta primacía de los expertos es que profundiza la gravedad de la incomunicación reiteradamente aludida en estas páginas. Más allá de la distorsión prevaleciente alrededor de su imagen pública (pues los expertos no están exentos per se de identificarse con cualquier proyecto político) lo que ocasiona su inusitado protagonismo es el abandono del interés por cualquier reflexión con pretensiones de globalidad. Simplemente no es de su interés. Por otro lado, soslayan la interrogación por el hombre, sus reflexiones están desprovitas de un carácter antropocentrista, tan necesario hoy en día. Si bien los ideólogos tampoco fueron muy productivos en ese tipo de indagación, esta carencia se profundiza con los expertos.

Finalmente, el divorcio o, en el mejor de los casos, la poca comunicación entre intelectuales y formación de una opinión pública característica del proceso peruano, se agudiza dado que los expertos ponen el privilegio de su atención en las esferas del poder, no porque quieran comunicarse con la sociedad y fracasen en su intento, sino porque es ahí, en la arena estatal, donde se encuentra su campo natural de 
reproducción. La comunicación con la sociedad deviene irrelevante para ellos. De este modo, no contribuyen a la formación de un lenguaje compartido, a la expansión de valores comunes, a generar modelos de hombres ideales. En otras palabras, el interés humanista termina siendo aplastado por la razón técnocrática.

El resultado final es que ni la actividad intelectual ni la política son vistas como espacios plausibles de acudir para la creación de proyectos de sociedades. Tanto lo político como lo intelectual parecen haber perdido las claves que tradicionalmente le otorgaron su distintividad (al menos idealmente), esto es, la de proveer de dirección ya sea a la organización de la sociedad o de la cultura, sustrayéndose al papel de ser meros administradores de lo inmediato. Es decir, estamos ante la cercenación de la imaginación ante el porvenir.

Como se dice en el título de este artículo se trata de un simple esquema para profundizar en la naturaleza de la relación que los intelectuales establecen con la política en Perú. Son hipótesis lanzadas al aire que necesitan ser pensadas y contrastadas por medio del análisis histórico y sociológico, sea para desecharlas o corroborarlas.

El momento actual que vive el Perú bajo el gobierno de Alberto Fujimori, puede ser un acicate especial que nos ayude a repensar las tradicionales maneras que hemos tenido sobre esa relación que siempre, a lo largo de la historia y en toda sociedad, ha sido dificil, compleja y tensa. Como ya al- guien lo ha mencionado, su gobierno es el primero en el que los intelectuales no tienen participación. Esto puede resultar beneficioso para los propios intelectuales puesto que la distancia suele ser buena consejera para el análisis sereno. Al revés de lo que dice la letra del famoso bolero, la distancia no necesariamente es el olvido; puede representar posibilidades de conocimiento.

Por otro lado, los años inmediatamente próximos pueden significar el interludio necesario para que aquellos sectores sociales a los que he estado haciendo referencia constante, surgidos desde la experiencia migratoria, encuentren y produzcan sus expresiones genuinas, tanto intelectuales como políticas. Finalmente, reflexionar sobre los intelectuales en Perú, en el actual contexto, en el que queremos salir de una prolongada crisis pero que no sabemos ni cómo ni hacia adónde, puede ser sumamente útil. Seguir pensando sobre los intelectuales es un magnífico pretexto para reflexionar sobre nosotros mismos, tanto como individuos como comunidad.

\section{BIBLIOGRAFIA}

-Adrianzén, Alberto, "Pacto político y concertación. Juntar las piezas del rompecabezas", QueHacer, núm. 65, DESCO, Lima, marzo-abril de 1990.

-Anderson, Benedict, Comunidades imaginadas. Reflexiones sobre el origen y la difusión del nacionalismo, $\mathrm{FCE}$, México, 1993.

-Balmori, Diana et al., Las alianzas de familias y la formación de país en América Latina, FCE, México, 1990. 
-Benichou, Paul, La coronación del escritor. 1750-1830, FCE, México, 1990.

-Bourdieu, Pierre, Campo de poder y campo intelectual, Folios, Buenos Aires, 1983.

-Brading, David A., Orbe indiano. De la monarquía católica a la república criolla, 1492-1867, FCE, México, 1991

-Burga, Manuel y Alberto Flores Galindo, Apogeo y crisis de la república aristocrática, Ed. Rickchay Perú, Lima, 1980.

-Coser Lewis, A., Hombres de ideas. El punto de vista de un sociólogo, FCE, México, 1966.

-Degregori, Carlos Iván, Qué dificil es ser Dios. Ideología y violencia política en Sendero Luminoso, El Zorro de Abajo, Lima, 1989.

, Cecilia Blondet y Nicolás Lynch, Conquistadores de un nuevo mundo. De invasores a ciudadanos en San Martín de Porras, IEP, Lima, 1986.

-De Soto, Hernando, El otro sendero, Ed. El Barranco, Lima, 1986.

-Durkheim, Emile, Las formas elementales de la vida religiosa, Alianza Editorial, Madrid, 1993.

-Flores Galindo, Alberto, Buscando un Inca, IIA, Lima, 1987.

-Franco, Carlos, "Nación, Estado y clases en el Perú de los ochenta", Socialismo y Participación, núm. 29, Lima, marzo de 1985.

, La otra modernidad. Imágenes de la sociedad peruana, CEDEP, Lima, 1991.

, "El sentido del velasquismo en la construcción de una comunidad nacional-ciudadana en el Perú", Socialismoy participación, núm. 63, Lima, noviembre de 1993.

-Fuentes, Carlos, Valiente mundo nuevo. Épica, utopía y mito en la novela hispanoamericana, FCE, México, 1994.

-Gonzáles, Osmar, "La seducción de la democracia. Socialismo y Nueva Izquierda en el Perú", Perfiles Latinoamericanos, año 3, núm. 5, Flacso-Sede México, diciembre de 1994.

"Señales sin respuesta. Los zorros y el pensamiento socialista en el Perú. 1968-1989", tesis de maestría en Ciencias Sociales, Flacso-Sede México, 1994.

"La academia y el ágora. En torno a intelectuales y política", en Etcétera, núm. 136, México, 7 de sept. de 1995.

-Hernández, Max, Memoria del bien perdido. Conflicto, identidady nostalgia en el Inca Garcilaso de la Vega, IEP-BPP, Lima, 1993.

-López, Sinesio, "Intelectuales y políticos en el Perú en el siglo xx", en Adrianzen Alberto (comp.), Pensamiento político peruano. 1930-1968, DESCO, Lima, 1990. , "Movilización campesina, nación y democracia ${ }^{n}$, Allpanchis, núm. 33, Cusco, 1989.

-Matos Mar, José, Desborde popular y crisis del Estado. El nuevo rostro del Perú en la década del ochenta, IEP, Lima, 1980.

-Morse, Richard, Resonancias del nuevo mundo, Vuelta, México, 1995.

-Ong, Walter, Oralidady escritura. Tecnologías de la palabra, FCE, México, 1987.

-Pontificia Universidad Católica del Perú, La generación del 68. Hablan los protagonistas, Temas en Sociología, núm. 2, Lima, 1994.

-Portocarrero, Gonzalo y Patricia Oliart, El Perú desde la escuela, IAA, Lima, 1989.

-Rochabrún S., Guillermo, "La política de la sociología. Para una apreciación del caso peruano", "Apéndice" al libro del mismo autor, Socialidad e individualidad. Materiales para una sociología, PUCP, Lima, 1993.

-Sánchez, Luis Alberto, "Colofón" al libro de Luis E. Valcárcel, Tempestad en los Andes, Ed. Universo, Lima, 1972.

-Sarlo, Beatriz, Escenas de la vida posmoderna. Intelectuales, arte y videocultura en la Argentina, Ariel, Buenos Aires, 1994. 


\section{SECUENCIA}

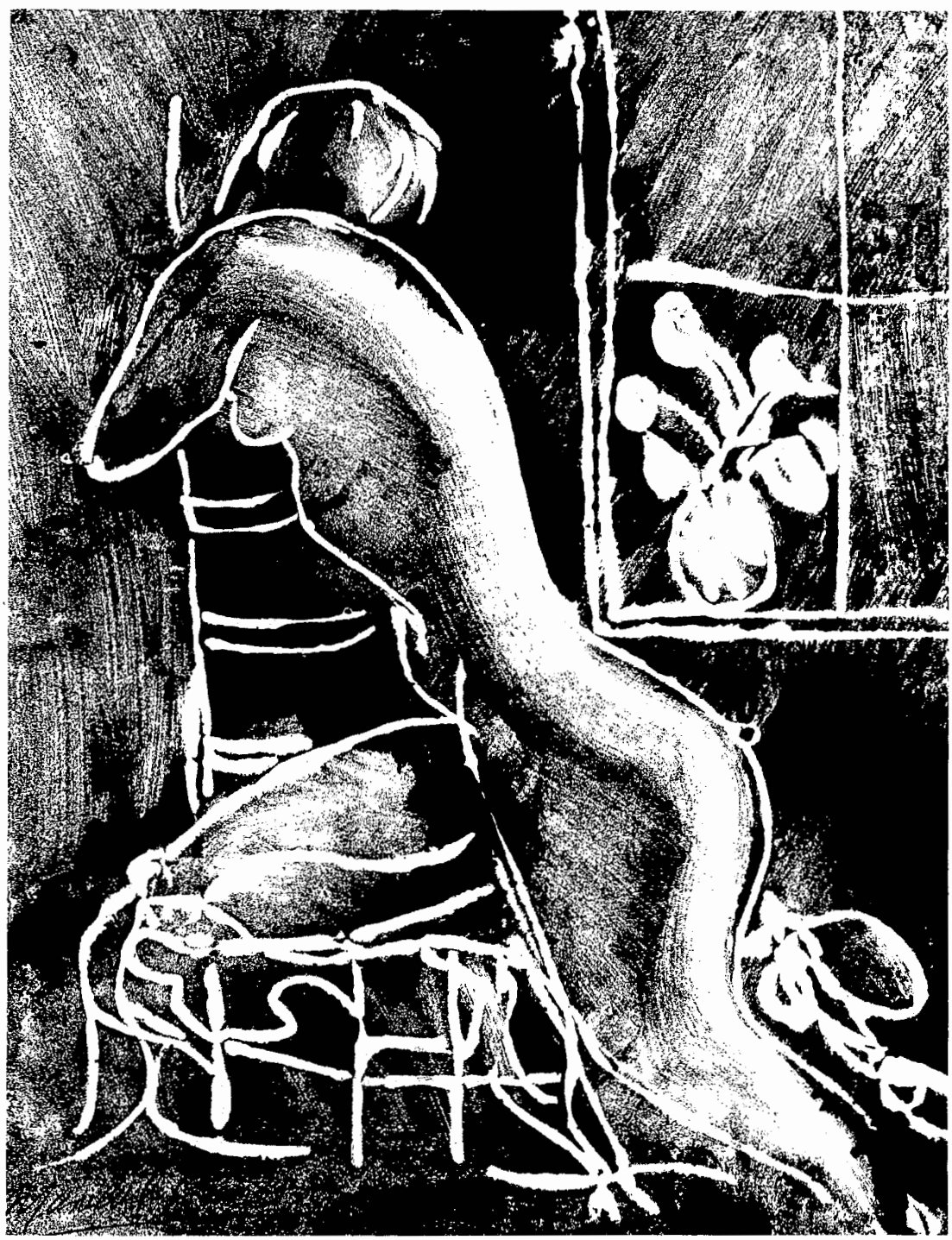

